\section{Burning bright}

\author{
How long will the investor exuberance driving public offerings of \\ biotech companies last? Brady Huggett investigates.
}

That recent enthusiasm for biotech companies' initial public offerings (IPOs) is a thing of wonder. Even gene therapy companies like bluebird bio of Cambridge, Massachusetts, have blazed onto the public exchanges. The company twice increased the anticipated amount of the offering before eventually pricing in June at $\$ 17$ per share, above its forecast range, and raising more than $\$ 116$ million. The underwriters picked up an expanded overallotment option- additional shares offered when demand is high-as the stock surged on the open market.

bluebird is just one of many biotech IPOs that have gone supernova in 2013 (Table 1). Biotech IPOs on NASDAQ and NYSE this year have raised, on average, $\$ 86$ million and collectively returned $62 \%$ over their IPO pricings at the end of the third quarter. Saying that the public market is receptive to early-stage biotechs is an understatement.

What's behind this heightened interest? And how long are the good times likely to last?

\section{The class of ' 13}

Biotech's climb is one part of the overall robust public markets this year. The S\&P 500 opened the year at 1,426.19, and by the end of the third quarter had grown to $1,681.55$ - a 17.9\% jump. But it is the biotech space that has astonished: the NASDAQ biotech index began the year at $1,460.20$; at the end of the third quarter it closed at $2,188.92$, a $50 \%$ leap over nine months. It has so far held onto these gains.

From among the 2013 life sciences IPOs, we selected those that are innovative and R\&Ddriven. We found subtle differences among firms that priced below, within or above their expected range (Supplementary Table 1), but the group in general has outperformed.

Biotech's current success is the result of many factors, but one element is serving as a backdrop: investor interest tends to be cyclical, and right now it appears to be biotech's turn. "It's almost mathematics," says Francesco De Rubertis, partner at Index Ventures of Geneva. "Many people basically predicted this a year ago. Board directors have been pushing companies to get ready for IPOs."

De Rubertis points to the pattern of investment flowing from internet and information technology (IT) to healthcare. In general, a peak for values in the IT space is followed some 6 to 12 months later by a peak in healthcare. A key moment was the Facebook IPO in 2012, he says, when the company priced shares at \$38the top of its suggested range-and raised $\$ 18.4$ billion, for a total valuation of $\$ 104$ billion, the largest ever for an American company going public. A lot of wealth was created in the IT space for investors, and that new money needed to be put to work. It is moving down the line to biotech stocks, he says.

Indeed, biotech 'windows' have routinely opened and closed in the past (Fig. 1), though how long the sash is up and what brings it down varies. Before the current boom in biotech IPOs, one train of thought was that windows would become a thing of the past; as investors became more seasoned, public offerings would be evaluated on the basis of a biotech business' fundamentals. That does not seem to be the case.

In the current period, adding fuel to the cyclical interest is a pent-up demand for good biotech stories. There have been just 65 innovative biotech IPOs in total for 2008-2012, compared to 101 IPOs in a single year during the 2000 biotech window. Even in tough times, an appetite remains among specialist investors.

This bottled demand is dovetailing with better performance from some of the mature biotech firms. Consider Regeneron, of Tarrytown, New York. At the beginning of 2011, the company's stock sat just below $\$ 33$. Since then, its

colorectal cancer drug, Zaltrap (ziv-aflibercept), has been approved; Ilaris (canakinumab) was cleared for juvenile rheumatoid arthritis; and Eylea (aflibercept) was approved for both wet age-related macular degeneration and macular edema from retinal vein occlusion. The company's stock closed above \$312 at the end of the third quarter.

Another example is Alexion of Cheshire, Connecticut, which from 2011 through the third quarter of 2013, had stock growth of $185 \%$, based on the potential of its blockbuster drug Soliris (eculizumab). Investors look for this sort of 'hockey stick' growth, but most public biotech firms such as these are already prohibitively expensive, which may be driving investors to the crop of young, innovative private companies in the hopes they follow a similar path.

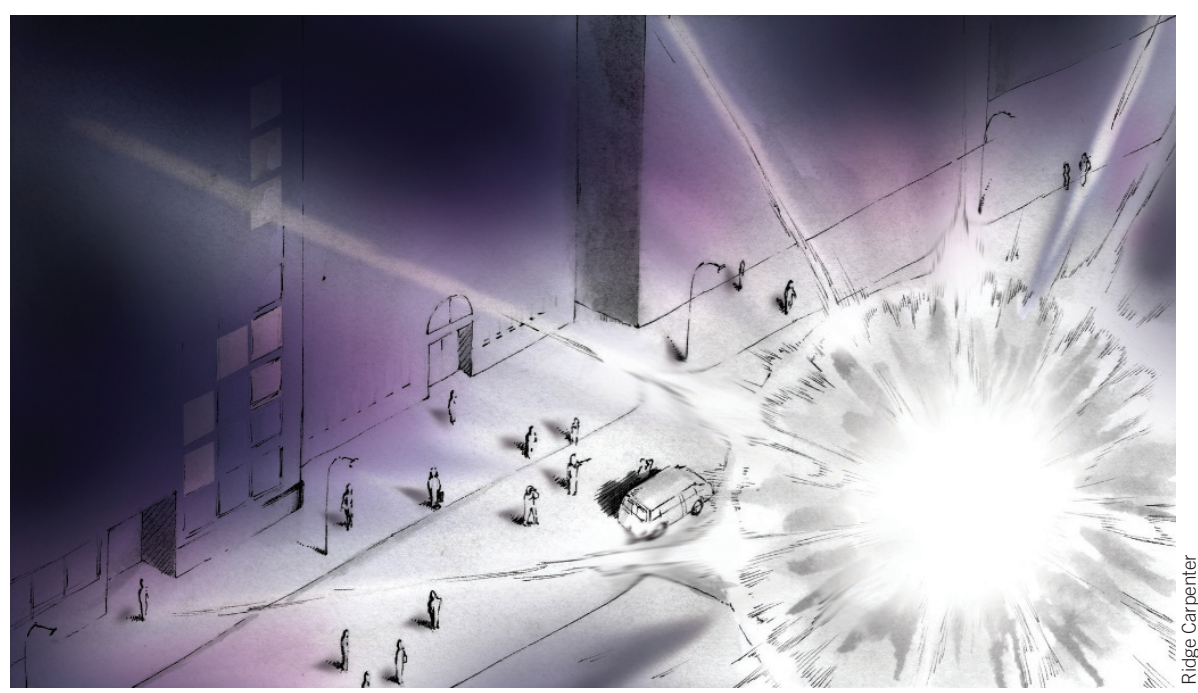

Biotech IPOs on US exchanges have been something to watch.

Much of the current group of early-stage companies were formed in a funding crucible. Since 2008, the total amount of money invested in young, innovative firms has fallen, and a decreasing number of venture capitalists have cornerstoned biotech creation (Nat. Biotechnol. 30, 395-400 (2013)). Bad news, of course, for those seeking investments, but good news for the surviving venture capitalists, who for years have been able to cherry-pick the most potentially disruptive technologies they saw. These prize projects are the ones now making their way into the public market.

This hasn't gone unnoticed by public investors, and indeed, in this cycle the markets seem to prefer early, science-based companies (Box 1). In some ways, says Annette Grimaldi, managing director at BMO Capital Markets in New York, young, cutting-edge companies make for more reassuring investments. "There is less of a binary risk for those anyway," she 
Table 1 Innovative biotech IPOs on NASDAQ and NYSE, 2013

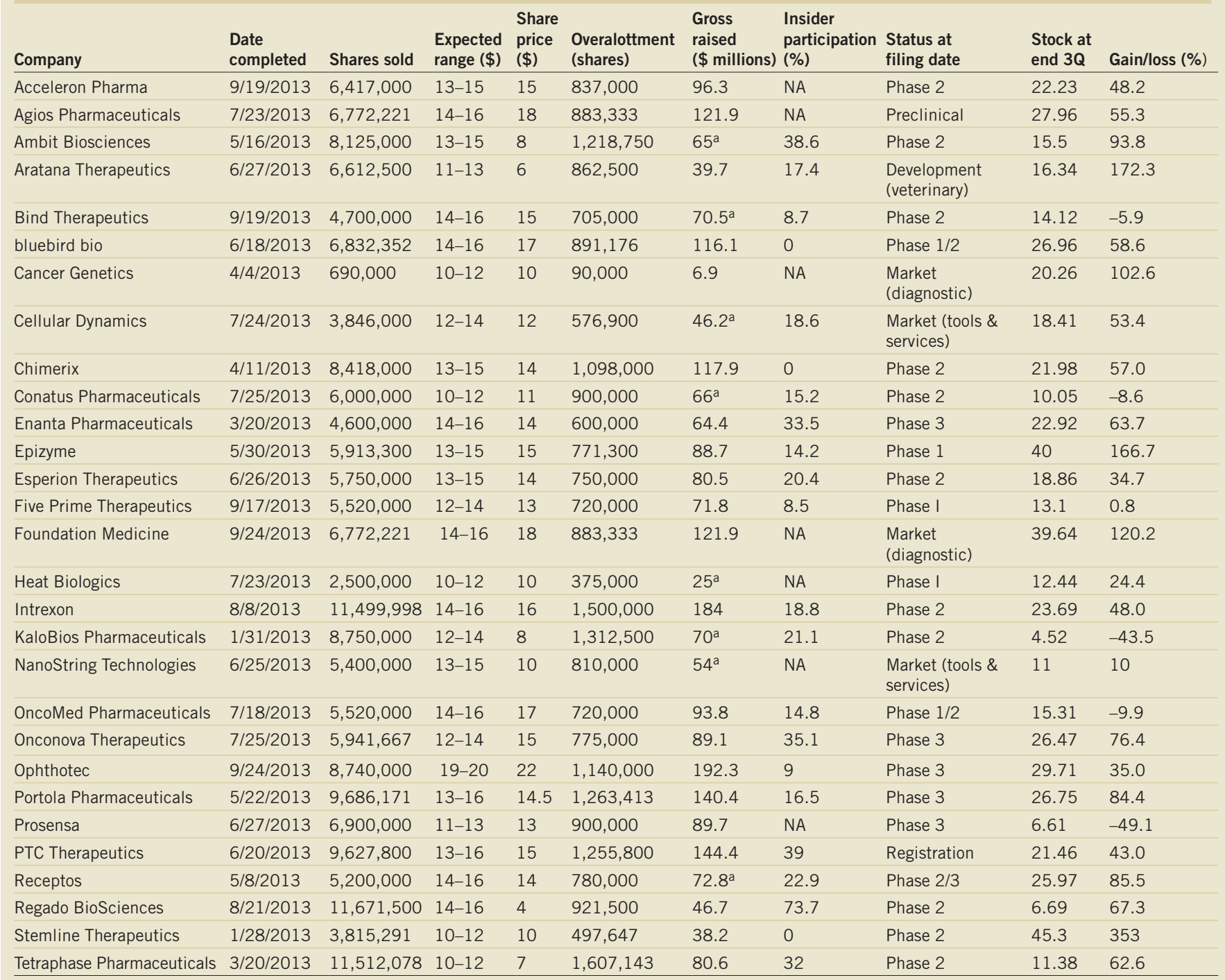

${ }^{a}$ Does not include overallotment or post-pricing shares sold to existing shareholders.

Source: BioCentury, BMO Capital Markets, company filings

says. "Investors are not worried about stepping away from their desk for a moment and coming back to find shares down $50 \%$ because of a failed trial."

The biggest portion of the companies floating in this cycle is oncology companies-17 of the 37 biotech IPOs through the third quarterthough there are platform technologies and firms chasing orphan disease, as well. Adam Bristol, portfolio manager at Aquilo Capital in San Francisco says that a "rather inelastic market demand and the ability to charge premium prices, especially in the US" still exists for orphan disease and oncology drugs. Although he notes that pushback on pricing may be coming, for now companies like Regeneron and Alexion have successfully transitioned into commercial-stage companies and are receiving high prices for their innovative drugs.
Beyond payor issues, a couple of other factors are helping to drive interest in biotech IPOs. One is a provision of the JOBS Act, enacted in April 2012. The provision expands the permissible communication between parties around an IPO, allowing companies to speak with investors about the possibility of participation without disclosing the potential IPO to the public. This has allowed emerging growth companies of all types, biotechs included, to 'test the waters' on joining the public markets, though discussing share price is disallowed. The extended runway has proved popular among biopharma firms, leading to some investors feeling swamped by meeting requests.

The second is the US Food and Drug Administration (FDA). The 37 drug approvals in 2012 ranked it as the best year in a decade, especially for biologics. Eleven of those were cancer drugs. Although drug approval numbers for 2013 are so far not looking as rosy, 2012 helped create the perception that the FDA is again a willing partner in clearing needed drugs.

\section{Who's buying?}

The frantic pace of IPOs, coupled with the high values being placed on newly public companies and the large amounts of capital being raised, has plenty of people comparing this open window to recent ones- the 2000 bubble and the generally receptive period of 2004-2007. The current environment falls somewhere in between those two. In 2000 there were 101 biotech IPOs on global exchanges, by our count (38 originated outside the US). The average amount raised was $\$ 85$ million (http:// www.nature.com/bioent/2003/030101/full/ nbt0601supp_BE18.html). In the 2004-2007 
window, the best year was the last, when there were 51 biotech IPOs, raising an average of $\$ 58$ million.

The first nine months of 2013 saw 36 IPOs on worldwide exchanges through three quarters, with the average amount raised at $\$ 73.8$ million.

A handful more have gone public in October, and another 10 were on file at the beginning of November, according to data from BMO Capital Markets (Table 2). It's not clear where total numbers for 2013 will end up, but Noubar Afeyan, managing partner and CEO of Flagship Ventures in Cambridge, Massachusetts, which has had five of their portfolio companies go public this year, doesn't see much of a comparison now with the zeal in 2000. "I don't see [a bubble] in the current crop of companies," he says, adding that the interest isn't due to "retail guys who suddenly think they need to get in [biotech]. To me, a bubble is what someone calls a cycle if they miss it, or it doesn't go their way."

This is the main difference from 2000, when the mom-'n-pop retail investors- cued in by media coverage on the decoding of the human genome-combined with generalist and specialist biotech investors to push the sector to those historical heights. By contrast, this window is being powered by the generalist investors, who, watching stocks rise overall, began relying on biotech to help beat the broader market performance.

The renewed interest from generalists is also seen in the drop in insider participation for successful IPOs. In harder times, innovative biotech IPOs were often propped up by already-present investors (generally venture capitalists) agreeing to buy into the public offering to get it completed. Brent Ahrens, general partner at Canaan in Menlo Park, California, notes that things have reversed now. Canaan portfolio company Chimerix, for example, went public in April, raising \$117.8 million, selling $8,418,000$ shares including the

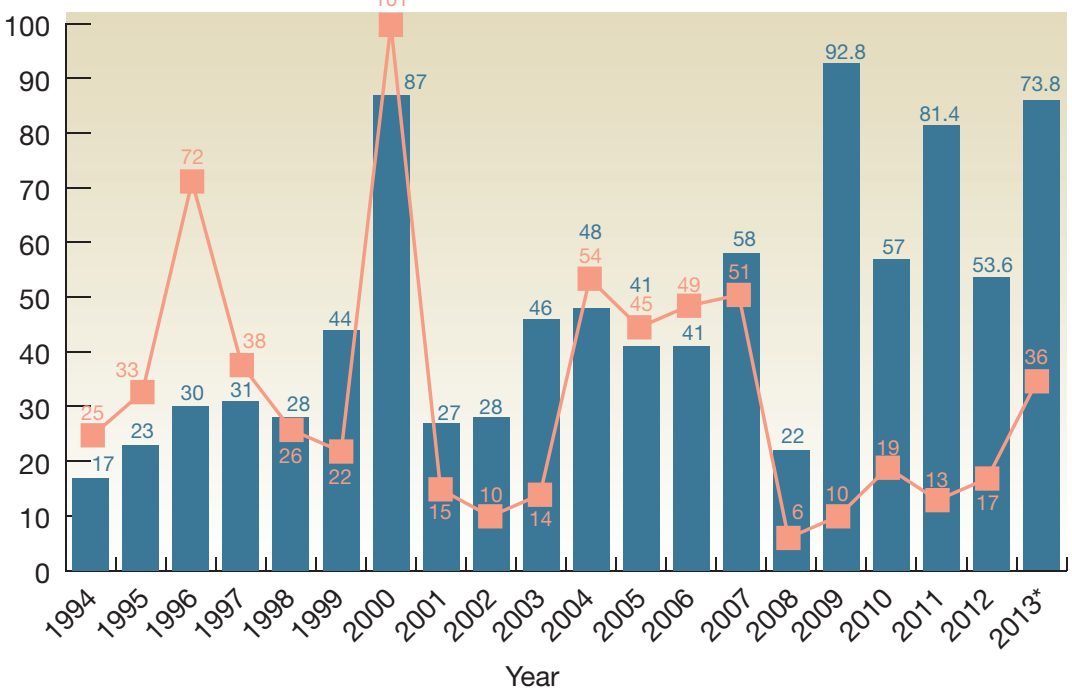

Number of IPOs

Average amount raised

Figure 1 Global biotech IPO windows. The cyclical nature of investing is observable in the biotech windows almost from the inception of the industry. * As of September 30, 2013.

\begin{tabular}{|c|c|c|c|c|}
\hline Company $^{a}$ & First filing date & Filing amount ( $\$$ millions) & Stage & Indication \\
\hline Ruthigen & $8 / 8 / 2013$ & 26.7 & Phase $1 / 2$ & Surgical infections \\
\hline Biocept & 9/23/2013 & 23 & Commercializing & Cancer diagnostic \\
\hline Relypsa & $9 / 27 / 2013$ & 138 & Phase 3 & Hyperkalemia \\
\hline Eaglet & 10/16/2013 & 69 & Phase 1 & Pain \\
\hline Recro Pharma & $10 / 24 / 2013$ & 28 & Phase $2 b$ & Post-operative pain \\
\hline Oxford Immunotec & $10 / 15 / 2013$ & 86.3 & Marketed & TB diagnostic \\
\hline Xencor & $10 / 11 / 2013$ & 69 & Phase $2 a$ & Autoimmune \\
\hline Trevena & $10 / 09 / 2013$ & 86.3 & Phase $2 \mathrm{a}$ & Acute heart failure \\
\hline Vital Therapies & $10 / 11 / 2013$ & 86.3 & Phase 3 & $\begin{array}{l}\text { Alcohol induced liver } \\
\text { disease }\end{array}$ \\
\hline TetraLogic & $10 / 18 / 2013$ & 103.5 & Phase 2 & Colorectal cancer \\
\hline
\end{tabular}

${ }^{a}$ Data are as of September 30, 2013. Since then, Karyopharma Therapeutics has priced its shares.

Source: BMO Capital Markets

overallotment. Of all those shares, not one was bought by inside investors. "I'm sure there was some [support] there if needed," he says, "but the company didn't need it."

\section{Box 1 Prepare for launch}

Agios, founded in 2007 and focused on cellular metabolism in cancer and inborn errors of metabolism, went public in July, raising $\$ 121.9$ million in gross proceeds, including a fully subscribed overallotment option for underwriters. The company had initially sought $\$ 86$ million, then $\$ 92$ million and raised the number of shares offered in the overallotment, as well. It priced shares well above its anticipated range.

This didn't happen by chance. From the moment David Schenkein came aboard as CEO in 2009, the company angled toward an IPO. "For the last two or three years, we met with 75 to 100 investors, some of them multiple times," Schenkein says. "And when we did, we said, "We're meeting with you because we want to go public. And we want you to know the team and the science'."
Still preclinical at filing, Agios was met with "a real enthusiasm to invest in real R\&D companies," Schenkein says. "And I get a sense there is a thirst for something novel; that helped Agios a lot."

The company priced the IPO with no insider participation-by design, Schenkein says, as it wanted to broaden its investor base. It already had three public investors on board through a private investment, and he admits those firms helped grease the skids for the IPO. When it came off, it rocketed. The company's stock opened on NASDAQ at $\$ 29$ and closed higher its first day.

Although a combination of factors played into the success, the biggest, Schenkein says, was the effort. "The market helped," he says, "but the most important element was the time we spent with [potential buyers] over the last three or four years." 
Table 32013 Innovative biotech IPOs on world exchanges

\begin{tabular}{|c|c|c|c|c|c|c|c|}
\hline Company (location) & Date completed & Shares sold & Filing price (\$/share) & Share price $(\$)$ & $\begin{array}{l}\text { Overalottment } \\
\text { bought }\end{array}$ & $\begin{array}{l}\text { Amount raised } \\
\text { (\$ millions) }\end{array}$ & Status at filing date \\
\hline $\begin{array}{l}\text { Cardio3 BioSciences } \\
\text { (Mont-Saint Guibert, Belgium) }\end{array}$ & $7 / 4 / 2013$ & $1,588,725$ & $21.61-24.66$ & 21.61 & 207,225 & 34.5 & Phase 3 \\
\hline Erytech Pharma (Lyon France) & $4 / 30 / 2013$ & $1,440,584$ & $13.75-16.63$ & 15.19 & NA & 21.8 & Phase 3 \\
\hline Immunicum (Gothenburg, Sweden) & $4 / 22 / 2013$ & $2,675,000$ & NA & 1.22 & NA & 3.3 & Phase $1 / 2$ \\
\hline Kadimastem (Ness Ziona, Israel) & $6 / 10 / 2013$ & $3,100,000$ & NA & 1.81 & NA & 5.6 & $\begin{array}{l}\text { Market (tools and } \\
\text { services) }\end{array}$ \\
\hline MedRx (Japan) & 2/13/2013 & $2,202,200$ & $8.57-10.71$ & 10.7 & 349,500 & 23.60 & Market (drug) \\
\hline PeptiDream & $5 / 31 / 2013$ & $2,105,000$ & $18.99-24.72$ & 24.72 & 405,000 & 52.4 & $\begin{array}{l}\text { Market (tools and ser- } \\
\text { vices) NA, not available. }\end{array}$ \\
\hline ReproCell (Yokohama, Japan) & $6 / 19 / 2013$ & 642,000 & $29.36-33.656$ & 33.65 & NA & 21.7 & $\begin{array}{l}\text { Market (tools and } \\
\text { services) }\end{array}$ \\
\hline
\end{tabular}

In fact, many have needed it less. Data from BMO Capital Markets, show that in 2010, of the nine companies that launched an IPO with available data, the average insider participation was $39.4 \%$, and all nine reported some level of participation. Of the 22 with reportable insider participation in 2013, the average amount so far has been 20.8\%; three reported no insider participation at all.

\section{The future}

Beyond the obvious benefits of raising money, a robust IPO market helps biotech in other ways. For example, it gives CEOs of private companies that might be targets for mergers or acquisitions bargaining power-they can honestly say there are other viable exits for its investors. Sizable venture capital exits from these IPOs could very well entice new money to contribute to fresh biotech venture capital funds. This could mean the long downward trend in venture capital funding for innovative early-stage biotech will reverse.

Still, as with any open window, the question becomes, How long do biotechs have? Looking at historical windows, the window in 2000 burned hottest, and it was also the shortest. Given that the current IPO market is burning pretty hot-remember those 29 new biotechs on US exchanges in 2013 are providing a collective $\sim 60 \%$ return on IPO price-one might assume this will not be a three- or four-year window. But it doesn't appear to be over yet.

"It will be interesting to see what happens in 2014," says BMO's Grimaldi, when investors reset all their returns to zero, and once again set out to prove their worth to clients. "I expect the flow to IPOs after [the annual JPMorgan Healthcare conference in January 2014] to be very heavy. We still feel the quality is pretty good for the companies going out," she says.

So far, the biotech rally is looking right past negative news. Prosensa, a company based in Leiden, the Netherlands, went public on NASDAQ on June 28, placing shares into the open market at $\$ 13$ apiece, where they quickly spiked to more than $\$ 33$ by the beginning of August. On September 20, it announced the failure of drisapersen, an antisense oligonucleotide, in a phase 3 trial for Duchenne muscular dystrophy patients with an amenable mutation. The company's stock fell $76 \%$, opening the next day at $\$ 5.67$. This was disastrous for Prosensa investors, but the overall market barely blinked. Ophthotec of New York and Cambridge, Massachusetts-based Foundation Medicine both completed IPOs on Sept. 24, pricing above their suggested range, and shares immediately climbed from there. This suggests that investor sentiment is focused on select companies, and strong offerings should still find favor.

What seems most likely for the IPO market, however, is that funds will just peter out - all the pent-up demand will be satisfied, and all that money looking for investment or reallocation will be used up. That's the theory that De Rubertis favors. He suggests this streak in the US will extend into 2014's first half before things "start drying up" in the third quarter. Money will begin to flow into Europe in mid-2014, he thinks, as Europe typically trails US investor sentiment by about 6 to 12 months, and where there has been less activity thus far (Table 3 ), but then he predicts it will slow there, too.

"This trajectory cannot go forever," he says. "Available capital will eventually go down. And we'll go back to a period of normal, natural growth."

Brady Huggett, Business Editor, Nature Biotechnology

Note: Any Supplementary Information and Source Data files are available in the online version of the paper (doi:10.1038/nbt.2766). 